\title{
Benefits of Regulating Hazardous Air Pollutants from Coal and Oil-Fired Utilities in the United States
}

\section{Citation}

Sunderland, Elsie M., Charles T. Driscoll, James K. Hammitt, Philippe Grandjean, John S. Evans, Joel D. Blum, Celia Y. Chen, et al. 2016. "Benefits of Regulating Hazardous Air Pollutants from Coal and Oil-Fired Utilities in the United States." Environmental Science \& Technology 50 (5) (February 5): 2117-2120. doi:10.1021/acs.est.6b00239.

\section{Published Version}

10.1021/acs.est.6b00239

\section{Permanent link}

http://nrs.harvard.edu/urn-3:HUL.InstRepos:37221734

\section{Terms of Use}

This article was downloaded from Harvard University's DASH repository, and is made available under the terms and conditions applicable to Open Access Policy Articles, as set forth at http:// nrs.harvard.edu/urn-3:HUL.InstRepos:dash.current.terms-of-use\#OAP

\section{Share Your Story}

The Harvard community has made this article openly available.

Please share how this access benefits you. Submit a story.

Accessibility 


\section{Benefits of Regulating Hazardous Air Pollutants from Coal and Oil-Fired Utilities in the}

\section{$2 \quad$ United States}

3 Elsie M. Sunderland ${ }^{1,2, *}$, Charles T. Driscoll, Jr. ${ }^{3, *}$, James K. Hammitt ${ }^{2}$, Philippe Grandjean ${ }^{2}$,

4 John S. Evans ${ }^{2}$, Joel D. Blum ${ }^{4}$, Celia Y. Chen ${ }^{5}$, David C. Evers ${ }^{6}$, Daniel A. Jaffe ${ }^{7}$, Robert P.

5 Mason $^{8}$, Shaun Goho ${ }^{9}$, and Wendy Jacobs ${ }^{9}$

$6{ }^{1}$ John A. Paulson School of Engineering and Applied Sciences, Harvard University, Cambridge

7 MA, 02138 United States

$8{ }^{2}$ T.H. Chan School of Public Health, Harvard University, Cambridge MA, 02138 United States

$9{ }^{3}$ Department of Civil and Environmental Engineering, Syracuse University, Syracuse, NY 13244

10 United States

$11{ }^{4}$ Department of Earth and Environmental Sciences, University of Michigan, Ann Arbor, MI

1248109 United States

$13{ }^{5}$ Department of Biological Sciences, Dartmouth College, Hanover, NH 03755 United States

$14 \quad{ }^{6}$ Biodiversity Research Institute, Portland, ME 04103 United States

$15{ }^{7}$ Science and Technology Program, University of Washington-Bothell, Bothell, WA 98011

$16{ }^{8}$ Department of Marine Sciences, University of Connecticut, Groton, CT 06340 United States

$17{ }^{9}$ Emmett Environmental Law \& Policy Clinic, Harvard Law School, Harvard University,

18 Cambridge MA, 02138 United States

19

$20{ }^{*}$ Corresponding authors: ems@seas.harvard.edu and ctdrisco@syr.edu 


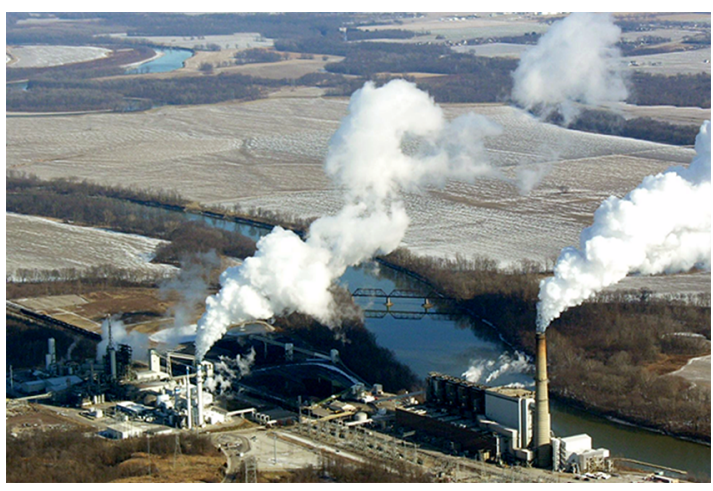


23 On June 29, 2015, the U.S. Supreme Court ruled that the Environmental Protection Agency

24 (EPA) acted unreasonably when it determined that cost was irrelevant to deciding whether it was

25 "appropriate" to regulate emissions of Hazardous Air Pollutants (HAPs) from coal and oil-fired

26 utilities (EGUs) (U.S. Supreme Court, Michigan v. EPA, 2015). According to the 1990 Clean Air

27 Act Amendments, EPA must make a preliminary determination, known as the "appropriate and

28 necessary" finding, before regulating EGUs. The Court ruled that EPA made a mistake at this

29 preliminary stage and sent the regulation, known as the Mercury and Air Toxics Standards

30 (MATS), back to the agency and ordered EPA to consider costs. The public comment period for

31 this proposal closed on January 15, 2016 and EPA aims to issue a final cost consideration and

32 renewed "appropriate and necessary" finding by April 15, 2016.

34 In its 2011 regulatory assessment ${ }^{1}$, EPA concluded that the monetized benefits for all air

35 pollutants (both direct benefits and co-benefits) associated with MATS range between $\$ 37$ and

$36 \$ 90$ billion and far exceed the costs of regulation. However, most of these quantified benefits

37 come from reductions in particulate emissions. Monetized benefits associated with reducing

38 HAP emissions in EPA's regulatory assessment ranged between $\$ 4$ - \$6 million, leading some

39 critics to argue that the rule was unreasonable. However, both the scientific community and EPA

40 have repeatedly emphasized the many additional, significant, unquantified benefits of this

41 regulation that further outweigh the costs. Even preliminary efforts to monetize these benefits

42 suggest they are substantially greater than the costs of the proposed regulation.

43

44 Although EGUs release a variety of HAPs, we will focus specifically on the benefits associated

45 with reducing emissions of mercury and exposures to its organic form, methylmercury, which is 
46 formed in aquatic ecosystems and bioaccumulates in food webs. Based on recent peer-reviewed

47 scientific literature, we find the monetized benefits for EGU mercury emissions reductions

48 identified by EPA in the regulatory impact analysis supporting MATS vastly understate the

49 benefits associated with reductions of those emissions.

50 Specifically we elaborate upon three key points below:

51 1. Recent research demonstrates that quantified societal benefits associated with declines in

52 mercury deposition attributable to implementation of MATS are much larger than the

53 amount estimated by EPA in 2011.

542 2. As-yet-unquantified benefits to human health and wildlife from reductions in EGU

55 mercury emissions are substantial.

56 3. Contributions of EGUs to locally deposited mercury have been underestimated by EPA's $57 \quad$ regulatory assessments.

58 1. Quantified societal benefits associated with declines in mercury deposition attributable

59 to implementation of MATS are much larger than the amount estimated by the EPA in

60 2011. $^{1}$

61 Due to data limitations and gaps in the available research, EPA's regulatory assessment only

62 considered a small subset of the public health and environmental risks associated with mercury

63 emissions from EGUs. Specifically, EPA monetized the value of IQ losses for children born to a

64 limited population of recreational fishers who consume freshwater fish during pregnancy from

65 watersheds where EPA had fish tissue data. The monetized value of benefits for this small

66 subpopulation was estimated between $\$ 4$ and $\$ 6$ million annually. ${ }^{1}$ 
67 If one considers instead all of the benefits of reducing EGU mercury emissions, recent research

68 confirms that the benefits are orders of magnitude greater than those quantified by EPA in 2011.

69 One study found that the cumulative U.S. economy-wide benefits associated with

70 implementation of MATS exceeded $\$ 43$ billion. $^{2}$ This value is far greater than EPA's estimate of

71 the costs associated with the regulation. Other work has estimated an annual benefit of $\$ 860$

72 million associated with a $10 \%$ reduction in methylmercury exposure in the U.S. population. ${ }^{3}$

\section{2. As-yet unquantified benefits to human health and wildlife are substantial.}

74 In part these estimates are so much greater than the quantified benefits identified in EPA's

75 regulatory assessment because they consider additional types of benefits from reducing EGU

76 mercury emissions. For example, many of these benefits are associated with adverse impacts of

77 methylmercury on cardiovascular health. EPA did not quantify cardiovascular effects in the

78 regulatory assessment. At that time, there was a split in the scientific evidence regarding the

79 significance of those impacts. On one side, an independent expert panel in 2011 asserted there is

80 sufficient scientific evidence to incorporate these outcomes in regulatory assessments. ${ }^{4}$ On the

81 other, a high-profile study of risks of cardiovascular disease associated with methylmercury

82 exposures in two U.S. cohorts found no evidence of adverse effects. ${ }^{5}$

83 There are several reasons, however, to conclude that the cardiovascular impacts are substantial

84 despite the latter study. First, the study included only low-to-moderate fish consumers and

85 therefore lacked the statistical power to detect effects seen in studies that included a greater

86 range in exposures (e.g., $\left.{ }^{6}\right)$. Second, it is challenging to isolate the neurodevelopmental and

87 cardiovascular impacts of methylmercury exposure from seafood consumption because seafood

88 also contains long-chained fatty acids (eicosapentaenoic acid and docosahexaenoic acid) that 
89 serve to mask those deleterious impacts. ${ }^{7,8}$ These confounding effects make it difficult for some

90 epidemiological studies to identify the negative health outcomes associated with methylmercury

91 exposures against the background of beneficial effects of consuming long-chained fatty acids in

92 seafood. However, this does not imply that exposures to methylmercury on its own are not

93 harmful, or that it does not reduce the benefits of an otherwise healthy food source. ${ }^{9,}{ }^{10}$ In

94 addition, imprecision in exposure biomarkers biases many epidemiological studies toward a null

95 finding rather than detection of adverse effects. ${ }^{11}$ We note that failure to find a statistically

96 significant effect is not evidence that no such effect exists, though it may provide evidence that

97 constrains the magnitude of the effect.

98 Although EPA's regulatory assessment did quantify one type of neurological effect (IQ loss)

99 among one group of fish consumers, its consideration of neurodevelopmental benefits from the

100 proposed rule is incomplete. For example, the assessment did not consider benefits associated

101 with reductions in methylmercury in coastal U.S. fisheries. It therefore significantly

102 underestimates the neurodevelopmental benefits of the rule, because marine fish account for

$103>90 \%$ of methylmercury intake by the U.S. population. ${ }^{12}$ These benefits are difficult to quantify

104 because they require attributing changes in methylmercury exposure from domestic,

105 international, and natural sources of mercury. Nevertheless, many species of marine fish eaten by

106 Americans spend a large portion of their lifecycle foraging in coastal U.S. domestic waters (Gulf

107 of Mexico, Atlantic and Pacific coastal waters). Recent research suggests the regulation of

108 domestic U.S. mercury emissions will have a substantial effect on mercury inputs to coastal

109 waters (see point 3 below). For example, a recent study reported marked decreases in mercury in

110 Atlantic coastal fisheries in response to decreases in mercury emissions. ${ }^{13}$ 
111 Furthermore, recent epidemiological data have revealed a suite of more sensitive

112 neurodevelopmental effects than full-IQ, the impact valued in EPA's 2011 regulatory

113 assessment. Even the original National Academy of Sciences Panel on the Toxicological Effects

114 of Methylmercury conceded that full-IQ was not the most sensitive indicator of

115 neurodevelopment. ${ }^{14}$ In addition, neurodevelopmental impacts of methylmercury have more

116 recently been documented at exposure levels below the reference dose established by the NRC

117 Panel in $2000 .{ }^{15}$ Similar to lead exposure, there is no evidence from epidemiological studies for a

118 health effects threshold, below which neurodevelopmental effects do not occur. ${ }^{16,17}$ As a result,

119 compared with EPA's regulatory assessment, a full quantification of the neurodevelopmental

120 impacts of EGU mercury emissions would need to take into account both other kinds of fish

121 consumption and effects other than reductions in IQ.

122 Many other benefits of regulating mercury emissions from EGUs have not been monetized on a

123 national scale due to the heterogeneity in effects across ecosystems, lack of data, and challenges

124 associated with monetization. These additional benefits include:

125 - Reductions in the deleterious impacts of methylmercury exposure on endocrine

126 function, ${ }^{18}$ risk of diabetes, ${ }^{19}$ and compromised immune health. ${ }^{20}$

127 - Benefits to fish and wildlife, including sensitive bird species (songbirds, loons), marine

128 mammals, fish, and amphibian populations threatened by high levels of mercury

129 contamination in many U.S. ecosystems. Emerging research on the ecological impacts of

130 methylmercury exposures indicates that adverse effects on the reproductive and

131 behavioral health of wildlife populations occur at low levels of environmental

132 exposure. ${ }^{21,22}$ 
133 3. Contributions of EGUs to locally deposited mercury have been underestimated by EPA's

134 regulatory assessments.

135 The regulatory assessment supporting MATS $^{1}$ also underestimates the benefits of reducing EGU

136 mercury emissions because it underestimated the portion of those emissions that are deposited to

137 the land and waters of U.S. ecosystems. Human and ecological health risks associated with

138 utility-derived mercury emissions are greatest in regions that are most affected by locally

139 deposited mercury. Some of the mercury emissions from EGUs are highly water-soluble and

140 locally deposited while the rest are emitted to the atmosphere as a stable, long-lived species that

141 is transported and distributed globally.

142 Benefits of MATS associated with declines in mercury deposition to U.S. ecosystems in the

143 regulatory assessment were based on atmospheric modeling that suggested global (non-U.S.)

144 anthropogenic sources would be most important for regional declines in deposition. However, for

145 the past two decades, mercury researchers have noted slow and steady declines in atmospheric

146 mercury concentrations in North America, Europe, and over the open oceans. Initial attempts to

147 rationalize these observations from a scientific perspective were confounded by a commonly

148 held (but incorrect) assumption among researchers that global mercury emission trends from

149 anthropogenic sources were steady or increasing over this same time period. Zhang et al. ${ }^{23}$

150 recently corrected an error in previous emissions inventories on the form of mercury released by

151 EGUs over time. This correction helps enable global models to reproduce the observed declining

152 atmospheric mercury trends and shows that local and regional mercury deposition to U.S.

153 ecosystems is much more influenced by domestic actions than previously assumed. 
154 Other new studies also support the premise that declining mercury emissions in the United States

155 will substantially reduce mercury deposition and biological exposures in U.S. ecosystems and

156 hence to U.S. populations. For example, several U.S. studies have measured substantial declines

157 in domestic atmospheric and ecologic mercury concentrations attributable to reductions in

158 mercury emissions from EGUs. Castro and Sherwell ${ }^{24}$ observed declines in atmospheric mercury

159 concentrations at a pristine site in Maryland downwind of power plants in Ohio, Pennsylvania,

160 and West Virginia. Drevnick et al. ${ }^{25}$ observed a mean $~ 20 \%$ decline in mercury accumulation in

161104 sediment cores from the Great Lakes regions attributable to domestic emissions reductions.

162 Evers et al. ${ }^{26}$ identified biological mercury hotspots in the northeastern United States driven

163 mainly by U.S. domestic emissions. Similarly, Hutcheson et al. ${ }^{27}$ noted declines in

164 methylmercury concentrations in freshwater fish in the United States concurrent with domestic

165 mercury emissions reduction. Cross et al. ${ }^{13}$ report marked decreases in mercury in Atlantic

166 coastal fisheries in response to decreases in mercury emissions.

167 Together, these new studies demonstrate that declines in mercury deposition to U.S. ecosystems

168 and resulting human and ecological exposures have been underestimated by the 2011 regulatory

169 impact assessment performed by EPA.

\section{References}

171 (1) U.S. Environmental Protection Agency (2011), Regulatory Impact Analysis for the Final

172 Mercury and Air Toxics Standards (US Environmental Protection Agency, Office of Air Quality

173 Planning and Standards, Research Triangle Park, NC). EPA-452/R-11-011. Available: http://

174 www3.epa.gov/mats/pdfs/20111221MATSfinalRIA.pdf.

175 (2) Giang, A., Selin, N. E. Benefits of mercury controls for the United States. Proc Natl Acad Sci

176 USA Early Edition 2015; http://www.pnas.org/cgi/doi/10.1073/pnas.1514395113. 
177 (3) Rice, G., Hammitt, J., Evans, J. A probabilistic characterization of the health benefits of 178 reducing methyl mercury intake in the United States Environ. Sci. Technol. 2010, 44, 5216-5224.

179 (4) Roman, H. A., Walsh, T. L., Coull, B. A., Dewailly, É., Guallar, E., Hattis, D., Mariën, K., 180 Schwartz, J., Stern, A. H., Virtanen, J. K., Rice, G. Evaluation of the cardiovascular effects of 181 methylmercury exposures: Current evidence supports development of a dose-response function 182 for regulatory benefits analysis. Environ Health Perspect 2011, 119, (5), 607-614.

183 (5) Mozaffarian, D., Shi, P., Morris, S. J., Spiegelman, D., Grandjean, P., Siscovick, D. S.,

184 Williett, W. C., Rimm, E. B. Mercury exposure and risk of cadivascular disease in two U.S. 185 cohorts. New England Journal of Medicine 2011, 364, 1116-1125.

186 (6) Choi, A. L.; Weihe, P.; Budtz-Jorgensen, E.; Jorgensen, P. J.; Salonen, J. T.; Tuomainen, T.

187 P.; Murata, K.; Nielsen, H. P.; Petersen, M. S.; Askham, J.; Grandjean, P. Methylmercury 188 exposure and adverse cardiovascular effects in faroese whaling men. Environ Health Perspect $1892009,117,(3), 367-372$.

190 (7) Mahaffey, K. R.; Sunderland, E. M.; Chan, H. M.; Choi, A. L.; Grandjean, P.; Marien, K.;

191 Oken, E.; Sakamoto, M.; Schoeny, R.; Weihe, P.; Yan, C. H.; Yasutake, A. Balancing the

192 benefits of n-3 polyunsaturated fatty acids and the risks of methylmercury exposure from fish 193 consumption. Nutr. Rev. 2011, 69, (9), 493-508.

194 (8) Oken, E.; Radesky, J. S.; Wright, R. O.; Bellinger, D. C.; Amarasiriwardena, C. J.; Kleinman, 195 K. P.; Hu, H.; Gillman, M. W. Maternal fish intake during pregnancy, blood mercury levels, and 196 child cognition at age 3 years in a US cohort. Am. J. Epidemiol. 2008, 167, (10), 1171-1181.

197 (9) Davidson, P. W.; Strain, J. J.; Myers, G. J.; Thurston, S. W.; Bonham, M. P.; Shamlaye, C. 198 F.; Stokes-Riner, A.; Wallace, J. M. W.; Robson, P. J.; Duffy, E. M.; Georger, L. A.; Sloane-

199 Reeves, J.; Cernichiari, E.; Canfield, R. L.; Cox, C.; Huang, L. S.; Janciuras, J.; Clarkson, T. W. 
200 Neurodevelopmental effects of maternal nutritional status and exposure to methylmercury from 201 eating fish during pregnancy. Neurotoxicology 2008, 29, (5), 767-775.

202 (10) Lynch, M. L.; Huang, L.-S.; Cox, C.; Strain, J. J.; Myers, G. J.; Bonham, M. P.; Shamlaye, 203 C. F.; Stokes-Riner, A.; Wallace, J. M. W.; Duffy, E. M.; Clarkson, T. W.; Davidson, P. W., 204 Varying coefficient models to explore interactions between maternal nutritional status and 205 prenatal methylmercury exposure in the Seychelles Child Development Nutrition Study. 206 Environmental Research 2011, 111, (1), 75-80.

207 (11) Grandjean, P.; Budtz-Jorgensen, E., An ignored risk factor in toxicology: The total 208 imprecision of exposure assessment. Pure Appl. Chem. 2010, 82(2), 383-391.

209 (12) Sunderland, E. M., Mercury exposure from domestic and imported estuarine and marine fish 210 in the U.S. seafood market. Environ Health Perspect 2007, 115, (2), 235-242.

211 (13) Cross, F. A.; Evans, D. W.; Barber, R. T., Decadal declines of mercury in adult bluefish 212 (1972-2011) from the mid-Atlantic coast of the U.S.A. Environ. Sci. Technol. 2015, 49, 90642139072.

214 (14) NRC, Toxicological Effects of Methylmercury. National Academy Press: Washington, DC, $2152000 ; \mathrm{p} 368$.

216 (15) Bellanger, M.; Pichery, C.; Aerts, D.; Berglund, M.; Castano, A.; Cejchanova, M.; Crettaz, 217 P.; Davidson, F.; Esteban, M.; Fischer, M. E.; Gurzau, A. E.; Halzlova, K.; Katsonouri, A.; 218 Knudsen, L. E.; Kolossa-Gehring, M.; Koppen, G.; Ligocka, D.; Miklavcic, A.; Reis, M. F.; 219 Rudnai, P.; Tratnik, J. S.; Weihe, P.; Budtz-Jorgensen, E.; Grandjean, P., Economic benefits of 220 methylmercury control in Europe: Monetary value of neurotoxicity prevention. Environmental 221 Health 2013, 12, (3), doi: 10.1186/1476-069X-12-3. 
222 (16) Karagas, M. R.; Choi, A. L.; Oken, E.; Horvat, M.; Schoeny, R.; Kamai, E.; Cowell, W.;

223 Grandjean, P.; Korrick, S., Evidence on the human health effects of low-level methylmercury

224 exposure. Environ Health Perspect 2012, 120, (6), 799-806.

225 (17) Grandjean, P.; Pichery, C.; Bellanger, M.; Budtz-Jorgensen, E., Calculation of mercury's

226 effect on neurodevelopment. Environ Health Perspect 2012, 120, (12), A452.

227 (18) Tan, S. W.; Meiller, J. C.; Mahaffey, K. R., The endocrine effects of mercury in humans and 228 wildlife. Critical Reviews in Toxicology 2009, 39, (3), 228-269.

229 (19) He, K.; Xun, P., Liu, K., Morris, S., Reis, J., Guallar, E. Mercury exposure in young

230 adulthood and incidence of diabetes later in life: the CARDIA trace element study, Diabetes

231 Care, 36: 1584-1589 (2013).

232 (20) J.F. Nyland, Fillon, M, Barbosa, R., Jr., Shirley, D.L., Chine, C., Lemire, M., Mergler, D., 233 Sibergeld, E.K. Biomarkers of methylmercury exposure and immunotoxicity among fish 234 consumers in the Amazonian Brazil, Envtl. Health Persp., 119(12): 1733-1738 (2011).

235 (21) Depew, D.C.; Basu, N.; Burgess, N.M.; Campbell, L.M.; Devin, E.W.; Drevnick, P.E.;

236 Hammerschmidt, C.R.; Murphy, C.A.; Sandheinrich, M.B.; Wiener, J.G. Toxicity of dietary

237 methylmercury to fish: derivation of ecologically meaningful threshold concentrations. Envtl.

238 Toxicology Chemistry 2012, 31(7): 1536-1547.

239 (22) Depew, D.C.; Basu, N.; Burgess, N.M.; Campbell, L.M.; Evers, D.C.; Grasman, K.A.;

240 Scheuhammer, A.M. Derivation of screening benchmarks for dietary methylmercury exposure

241 for the common loon (Gavia immer): Rationale for use in ecological risk assessment. Envtl.

242 Toxicology Chemistry 2012 31(10): 2399-2407.

243 (23) Zhang, Y.; Jacob, D.J.; Horowitz, H.M.; Chen, L.; Amos, H.M.; Krabbenhoft, D.P.; Slemr,

244 F.; St. Louis, V.; Sunderland, E.M. Observed decrease in atmospheric mercury explained by 
245 global decline in anthropogenic emissions. PNAS Early Edition 2016,

246 http://www.pnas.org/cgi/doi/10.1073/pnas.1516312113.

247 (24) Castro, M.S.; Sherwell, J. Effectiveness of emission controls to reduce the atmospheric

248 concentrations of mercury. Envtl. Sci. Tech. 2015, 49(24): 14000-14007.

249 (25) Drevnick, P.E.; Engstrom, D.R.; Driscoll, C.T.; Swain, E.B.; Balogh, S.J.; Kamman, N.C.;

250 Long, D.T.; Parsons, M.J.; Rolfhus, K.R.; Rossmann, R. Spatial and temporal patterns of

251 mercury accumulation in lacustrine sediments across the Great Lakes region. Environ. Poll. 2012

$252 \quad 161: 252-260$.

253 (26) Evers, D.C.; Han, Y-J.; Driscoll, C.T.; Kamman, N.C.; Goodale, W.; Fallon Lambert, K.;

254 Holsen, T.; Chen, C.Y.; Clair, T.A.; Butler, T. Biological mercury hotspots in the northeastern

255 United States and southeastern Canada. Bioscience 2007, 57(1): 29-43.

256 (27) Hutcheson, M.S.; Smith, M.C.; Rose, J.; Batdorf, C.; Pancorbo, O.; West, C.R.; Strube, J.;

257 Francis, C. Temporal and spatial trends in freshwater fish tissue mercury concentrations

258 associated with mercury emissions reductions. Envtl. Sci. Tech. 2014, 48: 2193-2202. 